Review

\title{
NASA Sees First in 2018 the Direct Proof of Ozone Hole Recovery
}

\author{
${ }^{1}$ Relly Victoria Petrescu, ${ }^{2}$ Raffaella Aversa, \\ ${ }^{2}$ Antonio Apicella and ${ }^{1}$ Florian Ion Tiberiu Petrescu \\ ${ }^{I}$ ARoTMM-IFToMM, Bucharest Polytechnic University, Bucharest, (CE), Romania \\ ${ }^{2}$ Department of Architecture and Industrial Design, Advanced Material Lab, \\ Second University of Naples, 81031 Aversa (CE), Italy
}

\author{
Article history \\ Received: 10-01-2018 \\ Revised: 16-01-2018 \\ Accepted: 22-01-2018 \\ Corresponding Author: \\ Florian Ion Tiberiu Petrescu \\ ARoTMM-IFToMM, \\ Bucharest Polytechnic \\ University, Bucharest, (CE), \\ Romania \\ E-mail: scipub02@gmail.com
}

Abstract: For the first time, scientists have shown through direct observations of the ozone hole by a satellite instrument, built by NASA's Jet Propulsion Laboratory in Pasadena, California, that levels of ozonedestroying chlorine are declining, resulting in less ozone depletion. Measurements show that the decline in chlorine, resulting from an international ban on chlorine-containing human-produced chemicals called Chlorofluorocarbons (CFCs), has resulted in about $20 \%$ less ozone depletion during the Antarctic winter than there was in 2005 -- the first year that measurements of chlorine and ozone during the Antarctic winter were made by NASA's Aura satellite. The ozone layer is the area of the terrestrial stratosphere, which is largely made up of ozone. This layer contains $90 \%$ of the ozone found in the atmosphere and absorbs $97-99 \%$ of high-frequency ultraviolet radiation. The ozone layer ranges from about $15 \mathrm{~km}$ to about $40 \mathrm{~km}$ altitude. Ozone is part of the gases that make up the atmosphere: It is born out of oxygen through photochemical reactions caused by solar radiation. The earth is surrounded by an ozone layer located at a very high altitude. This layer filters about two-thirds of the Ultraviolet (UV) radiation from the Sun. If all the rays reach Earth, it would be damaging to life on the planet. The ozone layer is located in the stratosphere, but the most concentrated is $20-25 \mathrm{~km}$. Basically, it is ozone and not pure ozone air, with a larger number of ozone molecules in the composition than the usual air (containing mainly nitrogen and oxygen). In the ozone layer there is a continuous transformation between different forms of oxygen. The usual oxygen molecules, $\mathrm{O} 2$, split into oxygen atoms, O. They merge with the oxygen molecules forming ozone, O3. Over time, ozone decomposes into normal oxygen $\mathrm{O} 2$ and single oxygen atoms, O. Over the past 40 years, industrial production using many chlorine-containing chemicals such as chlorofluorocarbons (CFCs) in sprays, refrigerants and solvents used in the electronics industry has increased. These substances have been banned under the Montreal Protocol. In September 2014, the United Nations and the World Meteorological Organization published a report on the evolution of the ozone layer, arguing that it could be rebuilt by the middle of the century as a result of the measures adopted by the Montreal Protocol. According to the report, the ozone layer has declined globally in the 1980s and early $1990 \mathrm{~s}$, has remained relatively unchanged since 2000 and could revert to the 1980 s before 2050 .

Keywords: NASA, Ozone, Ozone Hole, Ozone Hole Recovery 


\section{Introduction}

For the first time, scientists have shown through direct observations of the ozone hole by a satellite instrument, built by NASA's Jet Propulsion Laboratory in Pasadena, California, that levels of ozone-destroying chlorine are declining, resulting in less ozone depletion.

Measurements show that the decline in chlorine, resulting from an international ban on chlorinecontaining human-produced chemicals called Chlorofluorocarbons (CFCs), has resulted in about $20 \%$ less ozone depletion during the Antarctic winter than there was in 2005 -- the first year that measurements of chlorine and ozone during the Antarctic winter were made by NASA's Aura satellite.

"We see very clearly that chlorine from CFCs is going down in the ozone hole and that less ozone depletion is occurring because of it," said lead author Susan Strahan, an atmospheric scientist from NASA's Goddard Space Flight Center in Greenbelt, Maryland.

CFCs are long-lived chemical compounds that eventually rise into the stratosphere, where they are broken apart by the Sun's ultraviolet radiation, releasing chlorine atoms that go on to destroy ozone molecules. Stratospheric ozone protects life on the planet by absorbing potentially harmful ultraviolet radiation that can cause skin cancer and cataracts, suppress immune systems and damage plant life.

Two years after the discovery of the Antarctic ozone hole in 1985, nations of the world signed the Montreal Protocol on Substances that Deplete the Ozone Layer, which regulated ozone-depleting compounds.

Later amendments to the Montreal Protocol completely phased out production of CFCs.

Past studies have used statistical analyses of changes in the ozone hole's size to argue that ozone depletion is decreasing. This study is the first to use measurements of the chemical composition inside the ozone hole to confirm that not only is ozone depletion decreasing, but that the decrease is caused by the decline in CFCs.

The study was published Jan. 4 in the journal Geophysical Research Letters.

The Antarctic ozone hole forms during September in the Southern Hemisphere's winter as the returning Sun's rays catalyze ozone destruction cycles involving chlorine and bromine that come primarily from CFCs. To determine how ozone and other chemicals have changed year to year, scientists used data from JPL's Microwave Limb Sounder (MLS) aboard the Aura satellite, which has been making measurements continuously around the globe since mid-2004.

While many satellite instruments require sunlight to measure atmospheric trace gases, MLS measures microwave emissions and, as a result, can measure trace gases over Antarctica during the key time of year: The dark southern winter, when the stratospheric weather is quiet and temperatures are low and stable.
The change in ozone levels above Antarctica from the beginning to the end of southern winter -- early July to mid-September -- was computed daily from MLS measurements every year from 2005 to 2016.

"During this period, Antarctic temperatures are always very low, so the rate of ozone destruction depends mostly on how much chlorine there is," Strahan said. "This is when we want to measure ozone loss."

They found that ozone loss is decreasing, but they needed to know whether a decrease in CFCs was responsible.

When ozone destruction is ongoing, chlorine is found in many molecular forms, most of which are not measured. But after chlorine has destroyed nearly all the available ozone, it reacts instead with methane to form hydrochloric acid, a gas measured by MLS. "By around mid-October, all the chlorine compounds are conveniently converted into one gas, so by measuring hydrochloric acid we have a good measurement of the total chlorine," Strahan said.

Nitrous oxide is a long-lived gas that behaves just like CFCs in much of the stratosphere.

The CFCs are declining at the surface but nitrous oxide is not. If CFCs in the stratosphere are decreasing, then over time, less chlorine should be measured for a given value of nitrous oxide.

By comparing MLS measurements of hydrochloric acid and nitrous oxide each year, they determined that the total chlorine levels were declining on average by about $0.8 \%$ annually.

The $20 \%$ decrease in ozone depletion during the winter months from 2005 to 2016 as determined from MLS ozone measurements was expected. "This is very close to what our model predicts we should see for this amount of chlorine decline," Strahan said. "This gives us confidence that the decrease in ozone depletion through mid-September showed by MLS data is due to declining levels of chlorine coming from CFCs. But we're not yet seeing a clear decrease in the size of the ozone hole because that's controlled mainly by temperature after mid-September, which varies a lot from year to year."

Looking forward, the Antarctic ozone hole should continue to recover gradually as CFCs leave the atmosphere, but a complete recovery will take decades. "CFCs have lifetimes from 50 to 100 years, so they linger in the atmosphere for a very long time," said Anne Douglass, a fellow atmospheric scientist at Goddard and the study's co-author.

"As far as the ozone hole being gone, we're looking at 2060 or 2080 and even then there might still be a small hole." (Buis and Reiny, 2018; Aversa et al., 2017a; 2017b; 2017c; 2017d; 2017e; 2016a; 2016b; 2016c; 2016d; 2016e; 2016f; 2016g; 2016h; 2016i; 2016j; 2016k; 20161; 2016m; 2016n; 2016o; Berto et al., 2016a; 2016b; 2016c; 2016d; Mirsayar et al., 2017; Petrescu and Petrescu, 2016a; 2016b; 2016c; 2013a; 
$2013 \mathrm{~b} ; 2013 \mathrm{c} ; 2013 \mathrm{~d} ; 2012 \mathrm{a} ; 2012 \mathrm{~b} ; 2012 \mathrm{c} ; 2012 \mathrm{~d}$; 2011a; 2011b; Petrescu, 2016; 2012a; 2012b; 2009; Petrescu and Calautit, 2016a; 2016b; Petrescu et al., 2016a; 2016b; 2016c; Petrescu et al., 2017a; 2017b; $2017 \mathrm{c} ; 2017 \mathrm{~d} ; 2017 \mathrm{e} ; 2017 \mathrm{f} ; 2017 \mathrm{~g} ; 2017 \mathrm{~h} ; 2017 \mathrm{i}$; 2017j; 2017k; 2017l).

\section{Methods and Materials}

The ozone layer has shrunk by $20 \%$, thanks to the global destruction of chemical shatters, according to a NASA study (Fig. 1).

In the report published this week, scientists show that the decrease occurred during the winter months from 2005 to 2016. "We see very clearly that the level of chlorofluorocarbons in the ozone hole is decreasing and that ozone depletion is lower due to this", said Susan Strahan, from NASA's Goddard Space Flight Center, in a statement quoted by Euronews. The study, based on information provided by the Aura satellite, is the first to directly analyze chemical measurements and claims that the reduction in the hole in the ozone layer is the result of chlorofluorocarbon prohibition. The ozone layer protects the Earth from ultraviolet radiation, which can cause skin cancer and cataracts and can destroy the plants. A hole in this layer was discovered in the 1980s and attributed to chlorofluorocarbons. Although it moves, scientists warn that it will take decades for harmful substances to leave the atmosphere. Chlorofluorocarbons are kept between 50 and 100 years, so researchers say that in 2060 or 2080 the hole in the ozone layer will disappear.

The ozone layer is the area of the terrestrial stratosphere, which is largely made up of ozone. This layer contains $90 \%$ of the ozone found in the atmosphere and absorbs $97-99 \%$ of high-frequency ultraviolet radiation. The ozone layer ranges from about $15 \mathrm{~km}$ to about $40 \mathrm{~km}$ altitude.

Ozone is part of the gases that make up the atmosphere: It is born out of oxygen through photochemical reactions caused by solar radiation. The earth is surrounded by an ozone layer located at a very high altitude. This layer filters about two-thirds of the Ultraviolet (UV) radiation from the Sun. If all the rays reach Earth, it would be damaging to life on the planet. The ozone layer is located in the stratosphere, but the most concentrated is $20-25 \mathrm{~km}$. Basically, it is ozone and not pure ozone air, with a larger number of ozone molecules in the composition than the usual air (containing mainly nitrogen and oxygen).

In the ozone layer there is a continuous transformation between different forms of oxygen. The usual oxygen molecules, O2, split into oxygen atoms, $\mathrm{O}$. They merge with the oxygen molecules forming ozone, O3. Over time, ozone decomposes into normal oxygen $\mathrm{O} 2$ and single oxygen atoms, $\mathrm{O}$.

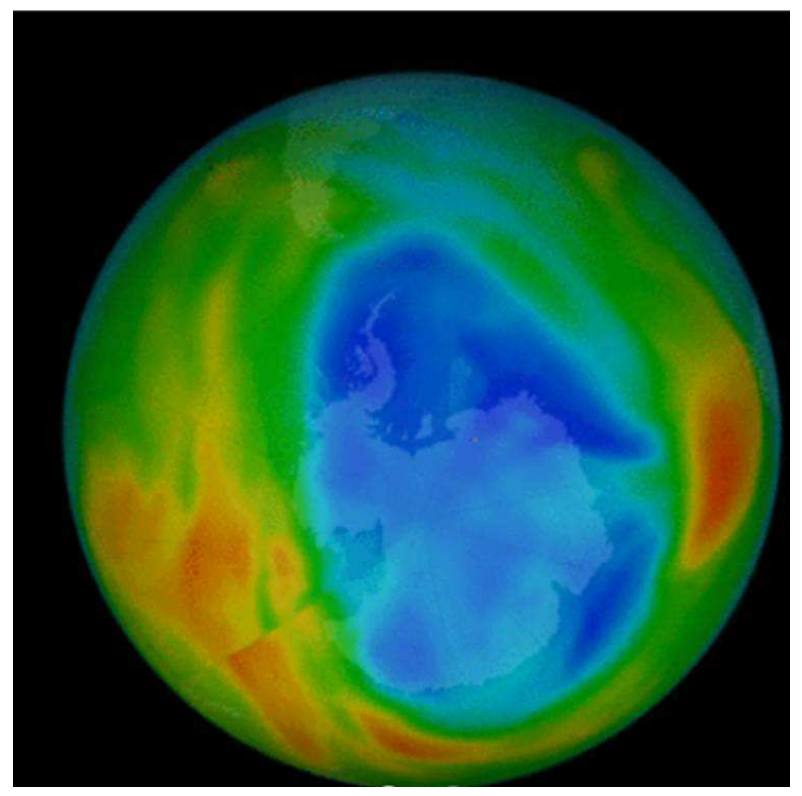

Fig. 1: Using measurements from NASA's Aura satellite, scientists studied chlorine within the Antarctic ozone hole over the last several years, watching as the amount slowly decreased. Credit: NASA's Goddard Space Flight Center/Katy Mersmann

Over the past 40 years, industrial production using many chlorine-containing chemicals such as Chlorofluorocarbons (CFCs) in sprays, refrigerants and solvents used in the electronics industry has increased. These substances have been banned under the Montreal Protocol. Chlorofluorocarbons (CFCs) are halogenated compounds derived from hydrocarbons wherein the hydrogen atoms have been replaced by chlorine and fluorine atoms. It's a type of fluorocarbons. A more common technical name for $\mathrm{CFC}$ is that of freon, a concrete example being freon-12 (dichlorodifluoromethane, $\mathrm{CCl}_{2} \mathrm{~F}_{2}$ ). There are also bromine-containing $\mathrm{CFCs}$ such as halothane $\left(\mathrm{C}_{2} \mathrm{HBrClF}_{3}\right)$. Since CFC contributes to the destruction of the ozone layer in the upper atmosphere, manufacturing of these compounds has been regulated by the Montreal Protocol, so they are replaced by other products such as HFCs. Analogous to simple alkanes, the carbon atoms in the CFC molecules have a tetrahedral geometry. Since chlorine and fluorine atoms have different sizes and charges different from hydrogen and their counterparts, methane-derived chlorofluorocarbons have almost perfect tetrahedral symmetry (Fig. 2).

Most chlorofluorocarbons are not chemically reactive and are stable at high temperatures. However, being so unreactive and inert, they can propagate in the stratosphere where, due to photochemical reactions, they cause decomposition and destruction of the ozone layer. 


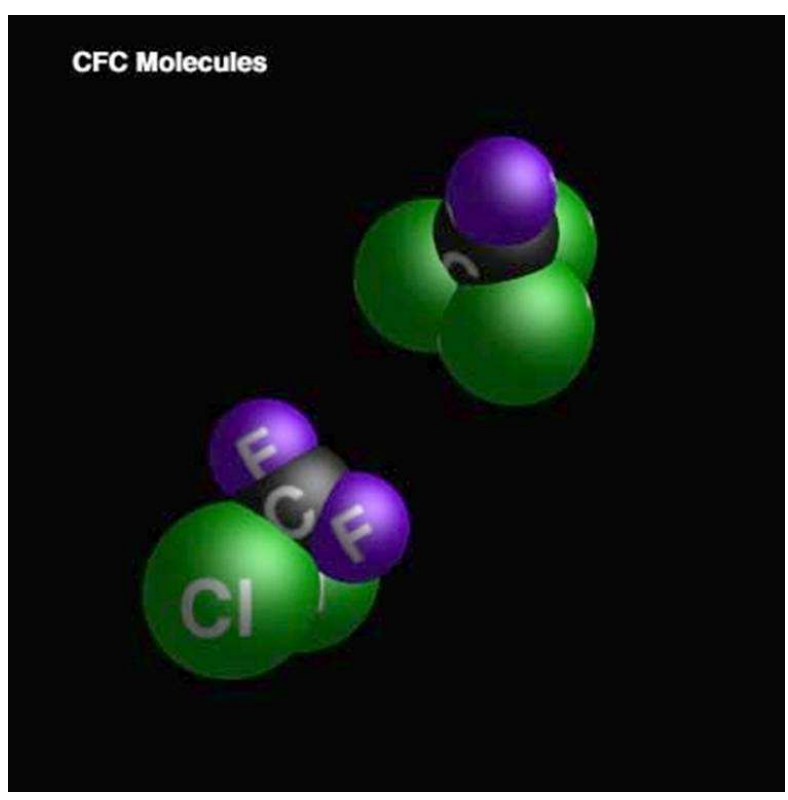

Fig. 2: The CFC structure indicates the substitution of the hydrogen atoms with chlorine and fluorine atoms; in the picture, the freon-11 (up) and freon-12 (bottom) molecules

The Montreal Protocol on Substances that Deplete the Ozone Layer (a protocol to the Vienna Convention for the Protection of the Ozone Layer) is an international treaty designed to protect the ozone layer by gradually stopping the production of several substances considered to be responsible for the destruction saddle. The Treaty was opened for signature on 16 September 1987 and entered into force on 1 January 1989, after which a first evaluation meeting took place in May 1989 in Helsinki. Since then, it has been revised seven times in 1990 (London), 1991 (Nairobi), 1992 (Copenhagen), 1993 (Bangkok), 1995 (Vienna), 1997 (Montreal) and 1999 (Beijing). It is hoped that if the treaty is respected, the ozone layer will replenish completely by 2050 . Due to its adoption and implementation on a large scale, the protocol has become an exceptional example of international cooperation, which Kofi Annan has said is "perhaps the most successful international agreement to date ". It was ratified by 196 states.

In September 2014, the United Nations and the World Meteorological Organization published a report on the evolution of the ozone layer, arguing that it could be rebuilt by the middle of the century as a result of the measures adopted by the Montreal Protocol. According to the report, the ozone layer has declined globally in the 1980 s and early 1990s, has remained relatively unchanged since 2000 and could revert to the $1980 \mathrm{~s}$ before 2050 (Fig. 3).

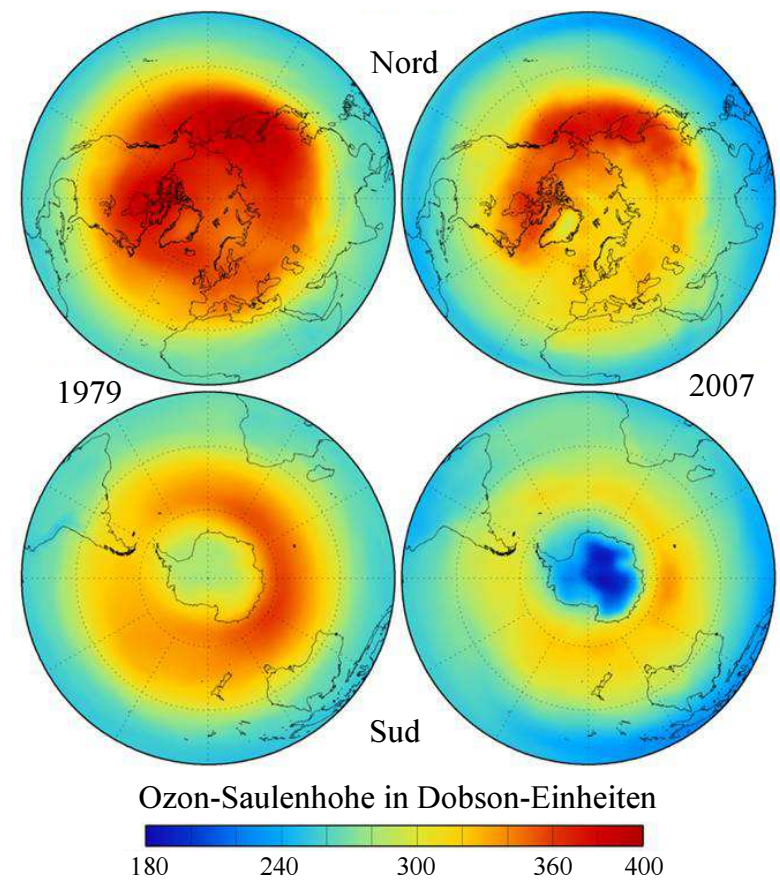

Fig. 3: The ozone layer in the Northern (Upper) and Southern (Lower)

The United Nations (abbreviated: UN) is the most important international organization in the world. Founded in 1945, after the Second World War, it has today 194 member states. Its founding consisted of the signing, by its founding members, of the United Nations Charter. According to this document, the UN has the mission to ensure "world peace", "respect for human rights", "international cooperation" and "respect for international law". The headquarters of the organization is in New York. The UN uses 6 official languages: Arabic, Chinese, English, French, Russian and Spanish. Almost all official meetings are translated simultaneously into these languages. Almost all papers or "online" documents are translated into these six languages. Depending on circumstances, some conferences and working documents are translated only in English, French or Spanish. In September 2014, the United Nations and the World Meteorological Organization published a report on the evolution of the ozone layer.

Ozone is the second allotropic form of oxygen, consisting of three atoms. Its chemical formula is O3. Its molecule is unstable and decomposes after a short time in diatomic oxygen. It is a powerful oxidant, which is harmful to humans, causing headaches, being an irritant, caustic of the respiratory mucosa.

The ozone layer present in the earth's atmosphere acts as a filter that holds most of the sun's ultraviolet radiation, regulates the temperature in the atmosphere, with special implications for protecting the biosphere. 
Just because it is unstable, ozone is very rare and is found in the atmosphere (its highest concentration is the ozone layer), at the Earth's surface (at a rate of $1 \cdot 10-7 \%)$ and at $22 \mathrm{~km}$ of surface Earth (1: 10-6\%). Places where ozone may occur are the waterfalls and shores of the seas (resulting from ultraviolet rays) and fir forests (produced by the oxidation of turpentine and other organic compounds).

The presence of ozone in the atmosphere is due to the interaction between ultraviolet rays and atmospheric oxygen. These rays, characterized by a significant amount of energy, decompose the oxygen molecules into two atoms. Ozone is formed by the union of three such atoms, but it is unstable, so that the atoms again merge into oxygen molecules and the cycle repeats infinitely.

The ozone layer around the Earth protects the biosphere from the harmful effects of solar ultraviolet radiation (such as skin cancer) and potentially hazardous electromagnetic radiation.

Ozone formed near the earth is toxic, leading to difficulties or respiratory damage and destruction of plants.

In recent years, chemical pollution (especially freon) has led not only to global warming, but also to the destruction of the ozone layer, a phenomenon with negative effects such as:

- Disturbing the thermal equilibrium of the atmosphere

- Triggering acid rain

- the disappearance of some animal species

- Reducing the reproductive rate of animals

- Increased incidence of skin cancer and eye conditions such as: Conjunctivitis, cataracts

As a result of chlorofluorocarbon emissions, at the end of the 20th century, the phenomenon of atmospheric ozone depletion, especially above the Antarctic, was noted. This is also due to the presence of ice crystals in the polar ice stratospheric clouds.

Greenhouse effect is a term used to highlight the contribution of certain gases emitted naturally or artificially to warming the earth's atmosphere by altering the permeability of the atmosphere to the solar radiation reflected by the terrestrial surface. This phenomenon was discovered by Joseph Fourier in 1824.

In the Earth's atmosphere, the greenhouse effect was responsible for its sufficient heating to allow plant development as we know it today.

The main element responsible for producing the greenhouse effect is water vapor $(70 \%)$. The next share is carbon dioxide $(9 \%)$, followed by methane $(9 \%)$ and ozone $(7 \%)$.

Over the last half century, large amounts of carbon dioxide and methane have been emitted into the atmosphere, which have reduced the permeability of the atmosphere for the heat reflected by the Earth to space. This has led to the start of the so-called global warming phenomenon.

According to a study in 2007, 22\% of global greenhouse gas emissions come from agriculture, a percentage similar to that in the industrial sector but higher than in the transport sector. Cattle farming, especially transport and feeding, is responsible for $80 \%$ of greenhouse gas emissions from agriculture.

According to the IPCC Climate Change 2014: Mitigation of Climate Change, $62 \%$ of greenhouse gas emissions between 2000 and 2010 are carbon dioxide. Greenhouse gas emissions grew faster between 2000 and 2010 than in the previous three decades and nearly half of cardone dioxide emissions between 1750 and 2010 are due to the last 40 years.

One of the most important global environmental issues is the greenhouse effect. The main cause of this effect is that enormous amount of carbon dioxide and other greenhouse gases that accumulate in the air layer forming a "patch". Substances that act: Freons, methane, ethane, nitrogen oxides, hydrogen, water. The properties of these substances are such that they allow the ultraviolet rays to pass very easily, reaching the surface of the soil, these rays transform into thermal energy and the thermal energy from the surface of the soil through this layer passes much harder in so the situation is created - the thicker the blanket, the warmer it is under it. This effect, called greenhouse effect, causes global climate change. The greenhouse effect also has positive properties, in the absence of these substances causing the effect the average temperature on the earth globe will be $15^{\circ} \mathrm{C}$. Currently, the amount of carbon dioxide is equal to $0.03 \%$. If this quantity is assumed to be doubled, in this situation the temperature of the earth globe may change by $1.3-3^{\circ} \mathrm{C}$. This increase in temperature can cause the glaciers to melt, so the ocean level can grow up to $6 \mathrm{~m}$.

\section{Results}

Researchers report that one of the biggest environmental issues that worried the planet over the years 1980-1990 has been a solution.

Research by US and UK scientists has shown that the size of the hole in the ozone layer has decreased on average by 4 million square kilometers since 2000 . The measurements have been made since September of each year, when the hole in the ozone layer starts to open.

The study, published in the journal Science, found that the gradual withdrawal of Chlorofluorocarbon (CFC) substances and plants means that the ozone layer "will recover as a structure, albeit at an extremely slow pace." Chlorofluorocarbons, previously used in aerosols and refrigerators can remain in the atmosphere for more than 50 years, meaning that the hole in the ozone layer will heal only in 2050 or 2060. 
The Montreal Protocol, a 1987 international treaty ratified by all UN member states, has encouraged nations to eradicate the use of CFC-based products.

After signing the agreement, fears have arisen that thinning of the ozone layer could cause serious human health problems, as well as environmental problems due to Ultraviolet (UV) rays that would reach the Earth's surface without ozone layer protection. The UN expects that 2 million cases of skin cancer per year were avoided by phasing out CFCs.

The hole in the ozone layer has formed above Antarctica because of the vast region of clouds that is born above the coldest continent on Earth. This cloud helps CFCs to persist in that area, which causes thinning of the ozone layer. The ozone layer is most thinner in the southern hemisphere during the spring.

Volcanic activity can also stimulate the depletion of the ozone layer. In 2015, scientists have alarmed that the largest hole in the ozone layer, measuring more than 20 million square kilometers, opened in October.

This result was caused by volcanic activity in Chile. When researchers surveyed September data and compared them to those in the same month over the past ten years, they noticed a consistent reduction, with the hole in the ozone layer opening up more and more every year.

"Volcanic activity plus man-made CFCs results in a toxic combination and Antarctica is deeply vulnerable," said Susan Solomon of the Massachusetts Institute of Technology (MIT) co-author.

"But when we looked at September, we saw how it diminished. It was interesting enough to see her shrink. Chemicals will break down over time."

It is believed that the extremely low temperatures in Antarctica create a "feedback" effect that amplifies the thinning of the ozone layer, creating clouds. The surplus of ultraviolet light would have caused placental changes, but the wildlife of the Antarctic, like the penguins, was not severely affected by the hole in the ozone layer.

"If there was to be a hole in the ozone layer anywhere in the world, that place had to be Antarctica because it was not a good place for life," Solomon said. "We realized that if we did not stop using these chemicals, we would have a crisis."

"Britain, for example, has 5\% less ozone than it was 30 years ago, but it would have been twice as bad if we had not stopped CFCs. There would be problems with skin cancer, eyesight and crops. We made a decision to deal with the problem and we have to congratulate ourselves for that, "said the researcher.

Solomon said he hoped that after the successful eradication of CFCs, a strong international action will be taken to prevent the dangerous consequences of climate change: "Visibly the way countries deal with global warming is different because the industry no longer using fuels is worth more than companies that continue to use these substances, "she said.

"But they are important parallels. It was amazing to see how innovation has solved the problem of CFCs, so we got rid of them, although we still have hair spray and air conditioning. We start to see the same thing about global warming. We should look at the ozone layer and realize that nations can work together and find solutions." (Buis and Reiny, 2018).

Greenhouse effect is a term used to highlight the contribution of certain gases emitted naturally or artificially to warming the earth's atmosphere by altering the permeability of the atmosphere to the solar radiation reflected by the terrestrial surface. This phenomenon was discovered by Joseph Fourier in 1824.

In the Earth's atmosphere, the greenhouse effect was responsible for its sufficient heating to allow plant development as we know it today.

The main element responsible for producing the greenhouse effect is water vapor $(70 \%)$. The next share is carbon dioxide $(9 \%)$, followed by methane (9\%) and ozone $(7 \%)$.

Over the last half century, large amounts of carbon dioxide and methane have been emitted into the atmosphere, which have reduced the permeability of the atmosphere for the heat reflected by the Earth to space. This has led to the start of the so-called global warming phenomenon.

According to a study in 2007, 22\% of global greenhouse gas emissions come from agriculture, a percentage similar to that in the industrial sector but higher than in the transport sector. Cattle farming, especially transport and feeding, is responsible for $80 \%$ of greenhouse gas emissions from agriculture.

According to the IPCC Climate Change 2014: Mitigation of Climate Change, $62 \%$ of greenhouse gas emissions between 2000 and 2010 are carbon dioxide. Greenhouse gas emissions grew faster between 2000 and 2010 than in the previous three decades and nearly half of cardone dioxide emissions between 1750 and 2010 are due to the last 40 years.

One of the most important global environmental issues is the greenhouse effect. The main cause of this effect is that enormous amount of carbon dioxide and other greenhouse gases that accumulate in the air layer forming a "patch". Substances that act: Freons, methane, ethane, nitrogen oxides, hydrogen, water. The properties of these substances are such that they allow the ultraviolet rays to pass very easily, reaching the surface of the soil, these rays transform into thermal energy and the thermal energy from the surface of the soil through this layer passes much harder in so the situation is created - the thicker the blanket, the warmer it is under it. This effect, called greenhouse effect, causes global climate change. The greenhouse effect also has positive properties, in the 
absence of these substances causing the effect the average temperature on the earth globe will be $-15^{\circ} \mathrm{C}$. Currently, the amount of carbon dioxide is equal to $0.03 \%$. If this quantity is assumed to be doubled, in this situation the temperature of the earth globe may change by $1.3-3^{\circ} \mathrm{C}$. This increase in temperature can cause the glaciers to melt, so the ocean level can grow up to $6 \mathrm{~m}$.

Global warming is the phenomenon of continual increase in average atmospheric temperatures in the immediate vicinity of the soil, as well as ocean water, observed in the last two centuries, but especially in recent decades. Global warming phenomena have always existed in Earth's history, being associated with the cosmic cosmic-solar phenomenon, alternating with small terrestrial glaciations associated with the minimal solar phenomenon.

The average air temperature near the Earth's surface increased $0.74 \pm 0.18^{\circ} \mathrm{C}$ in the last century.

If the observed heating phenomenon is almost unanimously accepted by scientists and decision-makers, there are various explanations for the causes of the process. The dominant opinion is that heating is due to human activity, especially by releasing carbon dioxide into the atmosphere by burning fossil fuels.

Intergovernmental Panel on Climate Change says that "most of the rise in average temperature in the second half of the 20th century is probably due to an increase in the greenhouse gas concentration of anthropogenic origin. They believe that natural phenomena such as solar variations and volcanism have had little effect of heating until the $1950 \mathrm{~s}$, but after the effect was mild cooling.

The theory of global anthropic warming is being challenged by some scientists and politicians, such as Claude Allègre or Václav Klaus. There are conspiracy theorists who think everything is just a pretext for world elites to demand pollution charges.

Global warming has supposed profound effects in many different areas. It causes or will cause elevation of sea level, climatic extremes, melting of glaciers, extinction of many species and changes in human health. Against the effects of global warming there is a sustained struggle, the central issue of which is the ratification by governments of the Kyoto Protocol on the reduction of pollutant emissions that influence the rate of warming.

Although it was claimed that in 2013 the Arctic ice cap will disappear definitively, it is now $60 \%$ more extensive than in 2012, with its borders almost uniting Canada and Russia (1.6 million $\mathrm{km}^{2}$ more). Several researchers say they are facing a global cooling down period that will affect the planet by the middle of the $21 \mathrm{st}$ century, which is why the UN Intergovernmental Panel on Climate Change (IPCC) convened an emergency meeting in late September 2013. Ed Hawkins of the University of
Reading says we will have to track the evolution of the Nordic glacier over the next 5 years to tell us about the global temperature trend: Growth or decline.

The Earth's climate has always undergone cyclical changes with cooling and heating periods. Changes have different durations, as well as different amplitudes. The following types of cycles are mentioned:

The day-night cycle (circadian cycle), in which temperatures can vary from a few degrees to a few dozen degrees. This cycle is too fast to be considered in the case of climate change.

The annual cycle (seasons), where variation in temperature and other parameters, e.g., carbon dioxide concentration) can be seen on a graph showing the influence of industrialization.

The solar cycle, with a duration of approx. 11 years, indicates a periodic variation in temperature, which can mask global warming.

The glacial cycle which stretches over thousands of years to hundreds of thousands of years causes great variations in climate.

The solar cycle is a variation of solar activity with an average duration of 11.2 years, but solar cycles of 8 to 15 years are known. It is assumed that a solar cycle is determined by its magnetic field, which is reversed every 11 years, a complete magnetic cycle lasting in fact 22 years. Solar activity is characterized by the number of sunspots, the number of solar rays and solar radiation. The best index is considered to be the $2.8 \mathrm{GHz}$ radiation, ie radiation with a wavelength of $10.7 \mathrm{~cm}$.

The influence of the solar cycle on the climate is not well known, but the lack of sunspots in the second half of the seventeenth century coincided with a very cold period, the Maunder period, called "little glaciation," or "the little ice age.

The study of the ancient climate, for example the quaternary (1.8 million years ago) to date, can be done on the basis of antarctic rocks, such as the Vostok station, which can extract ice from the depth of $3500 \mathrm{~m}$. The ice age is hundreds of thousands of years old. The isotopic composition of oxygen extracted from the ice allows reconstitution of atmospheric temperature over a period up to 700,000 years ago.

Glaciations were as follows: Mindel glaciation, which lasted from 650,000 to $350,000 \mathrm{BC}$, the Riss glaciation, which lasted from 300,000 to 120,000 BC. and glaciation Würm, which lasted between 80000 and $10000 \mathrm{BC}$. Also in the quaternary era, before the three men mentioned, glaciation Günz took place, which lasted between $900,000-700,000$ BC. During the quaternary period the temperature variations did not exceed $10^{\circ} \mathrm{C}$ and the temperature peaks never exceeded $+4^{\circ} \mathrm{C}$ compared to the current temperatures. In later periods, temperature variations reached $22^{\circ} \mathrm{C}$ and maximums $+8^{\circ} \mathrm{C}$. During these peaks, the ice has completely disappeared. 


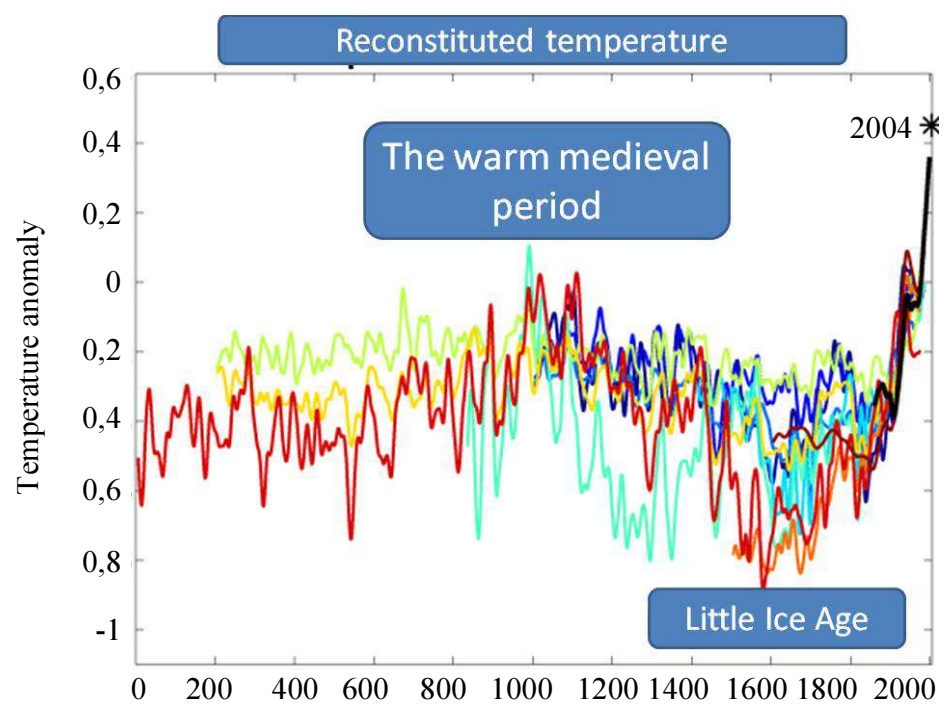

Fig. 4: Temperature in the past 2000 years, reconstituted. Reconstruction is based on the analysis of tree growth rings and the thickness of the glaciers

The glaciation study revealed the perfect correlation between temperature, ice stretching and carbon dioxide concentration in the atmosphere.

Figure 4 shows the temperature evolution over the past 2000 years.

The temperatures shown in the graph represent the averages over a 10-year interval. Since there are no direct temperature measurements during this period, the temperatures were reconstituted based on the measurement of the thickness of the tree growth rings and the thickness of the glaciers.

Dating of tree rings can be done based on the determination of carbon 14 .

Climate change in the Middle Ages was not as high as during the glaciation. However, during the last thousand years, a warm period was observed in the 10th and 11th centuries, a period called the medieval maximum. It is the era when the Vikings discovered Greenland, whose name "Green Country" indicates a vegetation landscape not covered by snow and ice.

Still, during the period (1550-1850), there was a cooling, the small ice age, in which the winters were very cold, especially between 1708 and 1709 .

According to the climatologists' reconstituted temperatures, the last decade of the twentieth century and the beginning of the 21 st century is the hottest period of the last 2000 years.

\section{Discussion}

You do not have to be a scientist to realize that something is happening to our planet, something that is not right (Too much pollution, too much human aggression on the blue planet). We begin to understand that we all have no place here and we will be practically locked up on the blue planet without enough food, clothing, housing, transport, energy, jobs and so slowly we are thinking more and more seriously about the mission of mankind, mission once humanitarian and now priority, to conquer outer space. As long as we have to live here all the more, it is imperative for us to correlate in such a way that we can properly share our existing resources, but also create new ones in the future.

With energy we started to move well, permanently enhancing the renewable and sustainable green energy, the hydro and nuclear fission and preparing in the future the energy future concentrated through the near-fusion nuclear reaction.

Drinking water resources are getting smaller, more limited, though paradoxically, our planet is water-filled with plenty of water, three-quarters of its surface being covered by seas and oceans, not to mention the multitude of lakes, glaciers, banks, waters and underground springs. Here the real problem is the diminishing of fresh, drinking water and natural cycle due to massive forest cuts. Deforestation and desertification have led to the reduction of drinking water, the dynamics of the water circuit in nature and rainfall. The rains have diminished in quantity and have been reduced at the same time, as a result of massive deforestations, often illegal, without governmental or world control.

To solve these major problems, it is imperative to relaunch the massive repopulations of the planet in all places. If the Arabs, an ancient and very civilized people, manage to turn the desert into forested and habitable areas, bringing water pumped out of the sea, not to mention the extension of the habitable land to them by creating new artificial islands, we can all use water seas and oceans to turn desserts into woodlands and habitable 
areas. Sea water and oceans can be separated from the salt in it to be filtered and sent as drinking water. However, it can be used directly to wet stretch cultures where there are no rivers and lakes, with the help of man-made installations, pumps, pipelines and irrigation. Young massive forests must appear again on the entire surface of our blue planet and this is as urgent as possible.

Programs limiting the use and burning of hydrocarbons are already active and controlled. However, there must also be actions to stop any nuclear or atomic experiment, as they are the first to blame for the destruction of protective ozone, for the reduction of the protective ozone layer and especially for its drilling.

Freon should not only be limited in use but even prohibited.

Climate changes due to external force, depending on the influence of orbital movement around the Sun, volcanic eruptions and greenhouse effect. The share of the various causes of heating is under study, but the consensus of scientists is that the main reason is the increase in greenhouse gas concentration due to human activities in the industrialization era. Especially in the last 50 years, when detailed data is available, this is obvious. However, there are other hypotheses that attribute warming to variations in solar activity.

We still cannot stop the volcanoes from erupting when they want it, nor use their energy, but we can replan the planet while limiting forest cuts, we can limit the burning of hydrocarbons, but especially of oil and coal, by massive introduction of energies new wind and photovoltaic around the globe.

We can also recycle paper, plastic products, iron and metals.

Like any new knowledge, chemistry has brought us a great deal of good on the planet but at the same time very bad in the last 50 years. Toxic and unhealthy, carcinogenic and all kinds of autoimmune diseases have been produced. Chemical and nuclear residues have been spilled into the waters of the seas and oceans by contaminating them so that we now eat contaminated water, drink contaminated water and consume contaminated food. Even if today there is severe control of nuclear and chemical residue pathways, accidents are still more or less happening and anyway water contamination followed by air, soil and subsoil has already produced disastrous consequences for a very long time.

\section{Conclusion}

As long as we have to live here all the more, it is imperative for us to correlate in such a way that we can properly share our existing resources, but also create new ones in the future.

With energy we started to move well, permanently enhancing the renewable and sustainable green energy, the hydro and nuclear fission and preparing in the future the energy future concentrated through the near-fusion nuclear reaction.

The arms race must cease, while the increase in funds allocated to medicine, for afforestation, the rapid development of green energy resources, science, in general, will have to become a permanent reality.

From time to time, we still have a good rain, even if less than 40-50 years ago, but there are signs of rebuilding and for terrestrial rains.

Year 2018 also began with a good sign in terms of lowering the hole in the Earth's shield of ozone.

It is in our power of all the inhabitants of the blue planet to care for it and make it even more beautiful than it once was.

\section{Acknowledgement}

We acknowledge and thank $\mathrm{Mr}$ Taher M. AbuLebdeh, Associate Prof at North Carolina A and T State Univesity, United States and Mr Muftah H. El-Naas PhD MCIC FICCE QAFCO Chair Professor in Chemical Process Engineering Gas Processing Center College of Engineering Qatar University and Ms Shweta Agarwala, Senior Research Scientist at Singapore Center for 3D Printing Nanyang Technological University Singapore for their suggestions and comments.

\section{Funding Information}

Research contract: Contract number 36-5-4D/1986 from 24IV1985, beneficiary CNST RO (Romanian National Center for Science and Technology) Improving dynamic mechanisms internal combustion engines. All these matters are copyrighted. Copyrights: 548-cgiywDssin, from: 22-042010, 08:48:48.

\section{Author's Contributions}

All the authors contributed equally to prepare, develop and carry out this manuscript.

\section{Ethics}

This article is original and contains unpublished material. The corresponding author confirms that all of the other authors have read and approved the manuscript and no ethical issues involved.

\section{References}

Aversa, R., F.I.T. Petrescu, R.V. Petrescu and A. Apicella, 2016a. Biomimetic FEA bone modeling for customized hybrid biological prostheses development. Am. J. Applied Sci., 13: 1060-1067. DOI: 10.3844/ajassp.2016.1060.1067 
Aversa, R., D. Parcesepe, R.V. Petrescu, G. Chen and F.I.T. Petrescu et al., 2016b. Glassy amorphous metal injection molded induced morphological defects. Am. J. Applied Sci., 13: 1476-1482.

DOI: 10.3844 /ajassp.2016.1476.1482

Aversa, R., R.V. Petrescu, F.I.T. Petrescu and A. Apicella, 2016c. Smart-factory: Optimization and process control of composite centrifuged pipes. Am. J. Applied Sci., 13: 1330-1341. DOI: 10.3844/ajassp.2016.1330.1341

Aversa, R., F. Tamburrino, R.V. Petrescu, F.I.T. Petrescu and M. Artur et al., 2016d. Biomechanically inspired shape memory effect machines driven by muscle like acting NiTi alloys. Am. J. Applied Sci., 13: 1264-1271. DOI: 10.3844/ajassp.2016.1264.1271

Aversa, R., E.M. Buzea, R.V. Petrescu, A. Apicella and M. Neacsa et al., 2016e. Present a mechatronic system having able to determine the concentration of carotenoids. Am. J. Eng. Applied Sci., 9: 1106-1111. DOI: 10.3844/ajeassp.2016.1106.1111

Aversa, R., R.V. Petrescu, R. Sorrentino, F.I.T. Petrescu and A. Apicella, 2016f. Hybrid ceramo-polymeric nanocomposite for biomimetic scaffolds design and preparation. Am. J. Eng. Applied Sci., 9: 1096-1105. DOI: 10.3844/ajeassp.2016.1096.1105

Aversa, R., V. Perrotta, R.V. Petrescu, C. Misiano and F.I.T. Petrescu et al., 2016g. From structural colors to super-hydrophobicity and achromatic transparent protective coatings: Ion plating plasma assisted $\mathrm{TiO}_{2}$ and $\mathrm{SiO}_{2}$ Nano-film deposition. Am. J. Eng. Applied Sci., 9: 1037-1045.

DOI: 10.3844/ajeassp.2016.1037.1045

Aversa, R., R.V. Petrescu, F.I.T. Petrescu and A. Apicella, 2016h. Biomimetic and evolutionary design driven innovation in sustainable products development. Am. J. Eng. Applied Sci., 9: 1027-1036. DOI: 10.3844/ajeassp.2016.1027.1036

Aversa, R., R.V. Petrescu, A. Apicella and F.I.T. Petrescu, 2016i. Mitochondria are naturally micro robots-a review. Am. J. Eng. Applied Sci., 9: 991-1002. DOI: 10.3844/ajeassp.2016.991.1002

Aversa, R., R.V. Petrescu, A. Apicella and F.I.T. Petrescu, 2016j. We are addicted to vitamins $\mathrm{C}$ and E-A review. Am. J. Eng. Applied Sci., 9: 1003-1018. DOI: 10.3844/ajeassp.2016.1003.1018

Aversa, R., R.V. Petrescu, A. Apicella and F.I.T. Petrescu, 2016k. Physiologic human fluids and swelling behavior of hydrophilic biocompatible hybrid ceramopolymeric materials. Am. J. Eng. Applied Sci., 9: 962-972. DOI: 10.3844/ajeassp.2016.962.972

Aversa, R., R.V. Petrescu, A. Apicella and F.I.T. Petrescu, 20161. One can slow down the aging through antioxidants. Am. J. Eng. Applied Sci., 9: 1112-1126. DOI: 10.3844/ajeassp.2016.1112.1126
Aversa, R., R.V. Petrescu, A. Apicella and F.I.T. Petrescu, $2016 \mathrm{~m}$. About homeopathy or $\ll$ Similia similibus curentur 》. Am. J. Eng. Applied Sci., 9: 1164-1172. DOI: 10.3844/ajeassp.2016.1164.1172

Aversa, R., R.V. Petrescu, A. Apicella and F.I.T. Petrescu, 2016n. The basic elements of life's. Am. J. Eng. Applied Sci., 9: 1189-1197. DOI: 10.3844/ajeassp.2016.1189.1197

Aversa, R., F.I.T. Petrescu, R.V. Petrescu and A. Apicella, 20160. Flexible stem trabecular prostheses. Am. J. Eng. Applied Sci., 9: 1213-1221. DOI: 10.3844/ajeassp.2016.1213.1221

Aversa, R., R.V.V. Petrescu, A. Apicella and F.I.T. Petrescu, 2017a. Nano-diamond hybrid materials for structural biomedical application. Am. J. Biochem. Biotechnol., 13: 34-41. DOI: 10.3844/ajbbsp.2017.34.41

Aversa, R., R.V. Petrescu, B. Akash, R.B. Bucinell and J.M. Corchado et al., 2017b. Kinematics and forces to a new model forging manipulator. Am. J. Applied Sci., 14: 60-80. DOI: 10.3844/ajassp.2017.60.80

Aversa, R., R.V. Petrescu, A. Apicella, I.T.F. Petrescu and J.K. Calautit et al., 2017c. Something about the $\mathrm{V}$ engines design. Am. J. Applied Sci., 14: 34-52. DOI: 10.3844/ajassp.2017.34.52

Aversa, R., D. Parcesepe, R.V.V. Petrescu, F. Berto and G. Chen et al., 2017d. Process ability of bulk metallic glasses. Am. J. Applied Sci., 14: 294-301. DOI: 10.3844/ajassp.2017.294.301

Aversa, R., R.V.V. Petrescu, B. Akash, R.B. Bucinell and J.M. Corchado et al., 2017e. Something about the balancing of thermal motors. Am. J. Eng. Applied Sci., 10: 200.217. DOI: 10.3844/ajeassp.2017.200.217

Berto, F., R.V.V. Petrescu and F.I.T. Petrescu, 2016a. A review of recent results on $3 \mathrm{D}$ effects. Am. J. Eng. Applied Sci., 9: 1247-1260. DOI: 10.3844/ajeassp.2016.1247.1260

Berto, F., R.V.V. Petrescu and F.I.T. Petrescu, 2016 b. Three-dimensional in bonded joints: A short review. Am. J. Eng. Applied Sci., 9: 1261-1268. DOI: 10.3844/ajeassp.2016.1261.1268

Berto, F., A. Gagani, R.V.V. Petrescu and F.I.T. Petrescu, 2016c. Key-hole notches in isostatic graphite: A review of some recent data. Am. J. Eng. Applied Sci., 9: 1292-1300. DOI: 10.3844/ajeassp.2016.1292.1300

Berto, F., A. Gagani, R. Aversa, R.V.V. Petrescu and A. Apicella et al., 2016d. Multiaxial fatigue strength to notched specimens made of 40CrMoV13.9. Am. J. Eng. Applied Sci., 9: 1269-1291. DOI: 10.3844/ajeassp.2016.1269.1291

Buis, A. and S. Reiny, 2018. NASA sees first direct proof of ozone hole recovery. Jet Propulsion Laboratory, Pasadena, California Institute of Technology. 
Mirsayar, M.M., V.A. Joneidi, R.V.V. Petrescu, F.I.T. Petrescu and F. Berto, 2017. Extended MTSN criterion for fracture analysis of soda lime glass. Eng. Fracture Mechan., 178: 50-59.

DOI: $10.1016 /$ j.engfracmech.2017.04.018

Petrescu, F.I.T., 2009. New aircraft. Proceedings of the 3rd International Conference on Computational Mechanics, Oct. 29-30, Brasov, Romania.

Petrescu, F.I.T., 2012a. Cold Nuclear Fusion. 1st Edn., Create Space, USA, ISBN-10: 1478234261, pp: 80.

Petrescu, F.I.T., 2012b. Particle annihilation-a source of renewable energy? Infinite Energy Magazine, LuLu Publishers, USA.

Petrescu, F.I.T., 2016 Valorificarea Traditiei Ingineresti Romanesti-I. 1st Edn., CreateSpace Independent Publishing Platform, ISBN-10: 1536889946, pp: 152.

Petrescu, F.I.T. and J.K. Calautit, 2016a. About nano fusion and dynamic fusion. Am. J. Applied Sci., 13: 261-266.

Petrescu, F.I. and J.K. Calautit, 2016b. About the light dimensions. Am. J. Applied Sci., 13:321-325. DOI: 10.3844/ajassp.2016.321.325

Petrescu, F.I. and R.V. Petrescu, 2011a. Memories about Flight. 1st Edn., CreateSpace, pp: 652.

Petrescu, F.I. and R.V. Petrescu, 2011b. Mechanical Systems, Serial and Parallel. 1st Edn., lulu.com Publisher, London, UK. ISBN-10: 1446600394, pp: 124.

Petrescu, R.V. and F.I.T. Petrescu, 2012a. Northrop. 1st Edn., Books on Demand, ISBN-10: 3848209322 , pp: 142 .

Petrescu, F.I. and R.V. Petrescu, 2012b. New Aircraft II. 1 st Edn., Books on Demand, pp: 138.

Petrescu, F.I. and R.V. Petrescu, 2012c. MecatronicaSisteme Seriale Si Paralele. 1st Edn., Create Space Publisher, USA, ISBN-13: 978-1-4750-6613-5, pp: 128.

Petrescu, F.I. and R.V. Petrescu, 2012d. Kinematics of the planar quadrilateral mechanism. ENGEVISTA, 14: 345-348.

Petrescu, R.V. and F.I. Petrescu, 2013a. Lockheed Martin. 1st Edn., CreateSpace, pp: 114.

Petrescu, R.V. and F.I. Petrescu, 2013b. Northrop. 1st Edn., CreateSpace, pp: 96.

Petrescu, R.V. and F.I. Petrescu, 2013c. The Aviation History or New Aircraft I Color. 1st Edn., CreateSpace, pp: 292.

Petrescu, F.I. and R.V. Petrescu, 2013d. Cinematics of the 3R Dyad. Engevista, 15: 118-124.

Petrescu, F.I. and R.V. Petrescu, 2016a. Parallel moving mechanical systems kinematics. ENGEVISTA, 18:455-491.

Petrescu, F.I. and R.V. Petrescu, 2016b. Direct and inverse kinematics to the anthropomorphic robots. ENGEVISTA, 18: 109-124.
Petrescu, F.I. and R.V. Petrescu, 2016c. Dynamic cinematic to a structure 2R. Revista Geintec-Gestao Inovacao E Tecnologias, 6: 3143-3154.

Petrescu, R.V.V., R. Aversa, A. Apicella, F. Berto and S. Li et al., 2016a. Ecosphere protection through green energy. Am. J. Applied Sci., 13: 1027-1032.

DOI: 10.3844/ajassp.2016.1027.1032

Petrescu, F.I.T., A. Apicella, R.V.V. Petrescu, S.P. Kozaitis and R.B. Bucinell et al., 2016b. Environmental protection through nuclear energy. Am. J. Applied Sci., 13:941-946.

DOI: 10.3844/ajassp.2016.941.946

Petrescu, R.V., R. Aversa, A. Apicella and F.I. Petrescu, 2016c. Future medicine services robotics. Am. J. Eng. Applied Sci., 9: 1062-1087. DOI: 10.3844/ajeassp.2016.1062.1087

Petrescu, R.V., R. Aversa, B. Akash, F. Berto and A. Apicella et al., 2017a. Forces of a 3R Robot. J. Mechatron. Robot., 1: 1-14. DOI: $10.3844 /$ jmrsp.2017.1.14

Petrescu, R.V., R. Aversa, B. Akash, F. Berto and A. Apicella et al., 2017b. Direct geometry and cinematic to the MP-3R systems. J. Mechatron. Robot., 1: 15-23. DOI: 10.3844/jmrsp.2017.15.23

Petrescu, R.V., R. Aversa, B. Akash, F. Berto and A. Apicella et al., 2017c. Dynamic elements at MP3R. J. Mechatron. Robot., 1: 24-37. DOI: $10.3844 /$ jmrsp.2017.24.37

Petrescu, R.V., R. Aversa, B. Akash, F. Berto, A. Apicella and F.I.T. Petrescu, 2017d. Geometry and direct kinematics to MP3R with $4 \times 4$ operators. J. Mechatron. Robot., 1: 38-46. DOI: $10.3844 / j m r s p .2017 .38 .46$

Petrescu, R.V., R. Aversa, A. Apicella, M.M. Mirsayar and S. Kozaitis et al., 2017e. Current stage in the field of mechanisms with gears and rods. J. Mechatron. Robot., 1: 47-57.

DOI: $10.3844 /$ jmrsp.2017.47.57

Petrescu, R.V., R. Aversa, A. Apicella, M.M. Mirsayar and S. Kozaitis et al., 2017f. Geometry and inverse kinematic at the MP3R mobile systems. J. Mechatron. Robot., 1: 58-65. DOI: 10.3844 jmrsp.2017.58.65

Petrescu, R.V., R. Aversa, A. Apicella, M.M. Mirsayar and S. Kozaitis et al., 2017g. Synthesis of optimal trajectories with functions control at the level of the kinematic drive couplings. J. Mechatron. Robot., 1: 66-74. DOI: 10.3844/jmrsp.2017.66.74

Petrescu, R.V., R. Aversa, A. Apicella, M.M. Mirsayar and S. Kozaitis et al., 2017h. The inverse kinematics of the plane system 2-3 in a mechatronic MP2R system by a trigonometric method. J. Mechatron. Robot., 1: 75-87. DOI: 10.3844/jmrsp.2017.75.87 
Petrescu, R.V., R. Aversa, A. Apicella, M.M. Mirsayar and S. Kozaitis et al., 2017i. Serial, anthropomorphic, spatial, mechatronic systems can be studied more simply in a plan. J. Mechatron. Robot., 1: 88-97. DOI: 10.3844/jmrsp.2017.88.97

Petrescu, R.V., R. Aversa, A. Apicella, M.M. Mirsayar and S. Kozaitis et al., 2017j. Analysis and synthesis of mechanisms with bars and gears used in robots and manipulators. J. Mechatron. Robot., 1: 98-108. DOI: 10.3844 jmrsp.2017.98.108

Petrescu, R.V., R. Aversa, A. Apicella, M.M. Mirsayar and S. Kozaitis et al., 2017k. Speeds and accelerations in direct kinematics to the MP3R systems. J. Mechatron. Robot., 1: 109-117. DOI: $10.3844 / j m r s p .2017 .109 .117$

Petrescu, R.V., R. Aversa, A. Apicella, M.M. Mirsayar and S. Kozaitis et al., 20171. Geometry and determining the positions of a plan transporter manipulator. J. Mechatron. Robot., 1: 118-126. DOI: $10.3844 / j m r s p .2017 .118 .126$

\section{Source of Figures}

Fig. 1:

https://www.jpl.nasa.gov/news/news.php?feature $=7033$

Fig. 2:

https://ro.wikipedia.org/wiki/Clorofluorocarbur\%C4\%83

\#/media/File:Chlorofluorocarbons_(space-

filling representation).jpg

Fig. 3:

https://ro.wikipedia.org/wiki/Stratul_de_ozon\#/media/Fil e:Ozone_layer_gmt_de.png

Fig. 4:

https://ro.wikipedia.org/wiki/\%C3\%8Enc\%C4\%83lzirea global\%C4\%83\#/media/File:2000_Year_Temperature Comparison_ro.png 